\section{Molecular investigation of zoonotic genotypes of Giardia intestinalis isolates in humans, dogs and cats, sheep, goats and cattle in Araçatuba (São Paulo State, Brazil) by the analysis of $\beta$-giardin gene fragments}

\author{
Elenir Alves Macedo de Godoy, ${ }^{1}$ \\ Juares Elias Santos Junior, ${ }^{1}$ \\ Marcus Vinícius Teresa Belloto, ${ }^{1}$ \\ Marcus Vinícius Proença de Moraes, ${ }^{1}$ \\ Gustavo Capatti Cassiano, ${ }^{1}$ \\ Aline Cardoso Caseca Volotão, ${ }^{2}$ \\ Maria Cecília Rui Luvizotto, ${ }^{3}$ \\ Claudia Márcia Aparecida Carareto, ${ }^{4}$ \\ Mônica Cristina de Moraes Silva, 5 \\ Ricardo Luiz Dantas Machado 1,4,5 \\ 'Faculdade de Medicina de São José do \\ Rio Preto, São José do Rio Preto, São \\ Paulo; ${ }^{2}$ Universidade Federal Fluminense, \\ Niterói, Rio de Janeiro; ${ }^{3}$ Universidade \\ Estadual Paulista, Araçatuba, São Paulo; \\ 4Universidade Estadual Paulista, São \\ José do Rio Preto, São Paulo; 5 Instituto \\ Evandro Chagas, Ananindeua, Pará, \\ Brazil
}

\section{Abstract}

In the period from July 2009 to October 2010, fecal samples from 61 animals and 154 humans from the municipality of Araçatuba (São Paulo State, Brazil) were studied. Fecal samples from animals were collected in the Municipal Animal Shelter and the Veterinary Hospital of the Universidade Estadual Paulista. Human fecal specimens were collected in playschools in the outskirts of the city by the private network of clinical analysis laboratories of the municipal. Diagnosis was done by optical microscopy using the Faust and Hoffmann, Pons and Janer techniques. The genotypes of Giardia intestinalis were characterized by PCR-RFLP and confirmed by sequencing the $B$-giardin gene. Human specimens were positive in $25.3 \%$ (39/154) of the cases with $26.8 \%(36 / 134)$ of the specimens from children and 15\% (3/20) from adults being positive. The frequency of $G$. intestinalis among the animals was 23.0\% (14/61). A total of 32 isolates of $G$. intestinalis obtained from human feces and six from dogs and cats were characteristic of the A genotype (AI and AIV/AIII). The results of this study in respect to frequency of giardiasis are similar to reported in most studies in Brazil. The prevalence observed in animal populations conforms to worldwide infection rates. $G$. intestinalis genotypes considered zoonotic were detected in both pets and humans from the city of Araçatuba, suggesting a possible zoonotic transmission of the parasite in the northwestern region of São Paulo State. The absence of these genotypes in farm animals may imply that they are not involved in the chain of transmission to humans in this region.

\section{Introduction}

Giardia intestinalis is a highly prevalent intestinal parasite in Brazilian children. It is responsible for cognitive disabilities and consequently delays in development thereby characterizing it as an important public health problem. ${ }^{1}$ Increased knowledge of the molecular characteristics of parasites of the genus Giardia has shown broad genetic diversity within the populations of $G$. intestinalis. ${ }^{2}$ Although Brazil is a continental-sized country and has characteristics ideal for the spread and perpetuation of giardiasis, few works on the molecular epidemiology of this parasite have been published.

The World Health Organization has considered the possibility of zoonotic transmission of G. intestinalis for more than 30 years, however even today there is no solid proof of this zoonotic transmission. ${ }^{3}$ Based upon the current characterization on the genetic groups of G. intestinalis and their prevalence in different animal species, including humans, it was proposed that there are four cycles of parasite transmission: between dogs and cats, only between humans, between farm animals and between wild animals. There is a possibility of transmission from one cycle to another both through contaminated water or directly. Thus, an understanding of how such cycles interact and what is the frequency of genotypes considered zoonotic are contemplated of fundamental importance. ${ }^{4}$

Our close relationship with pets and their ubiquitous distribution has resulted in dogs and cats involuntarily participating in the dissemination of more than 60 species of parasites to man including Giardia sp. ${ }^{5}$ Other factors involved in transmission are the great climatic, cultural and socioeconomic differences in Brazil. In most developed regions, veterinary services for pets are comparable to those found in developed countries. However in less developed regions, the infrastructure is precarious similar to poor countries where most people have no access to public health and veterinary services. ${ }^{6}$ Cattle infection rates around the world range from $2.2 \%$ in Poland to $58 \%$ in Australia. ${ }^{7,8}$ Guimarães et al. $^{9}$ described
Correspondence: Ricardo Luiz Dantas Machado, Instituto Evandro Chagas, BR316, Km 7, Zip code 67030-000, Levilândia, Ananindeua, Pará, Brazil. Tel. +55.913.214.2089.

E-mail: ricardomachado@iec.pa.gov.br

Key words: Giardia, zoonosis, genotypes, epidemiology, Brazil.

Acknowledgements: the Secretary of health of Araçatuba gave support in sample collection. The Authors wish to thank Mr. Flavio Paz e Silva of the Universidade Estadual Paulista, Botucatu, São Paulo and the Instituto Oswaldo Cruz, Rio de Janeiro, Brazil who kindly provided DNA of G. intestinalis utilized as positive control in the PCR reactions. Additionally thanks go to the Laboratory of molecular markers and Medical Bioinformatics (LMMB), Research in Genetics and Molecular Biology Unit and Neuromuscular Research Laboratory of the FAMERP for the analysis of genomic DNA, registration of the results of gels and supply of liquid nitrogen, respectively.

Contributions: the authors contributed equally.

Conflict of interests: the authors declare no potential conflict of interests.

Funding: this work has been supported by Conselho Nacional para o Desenvolvimento Científico e Tecnológico (CNPq), Brasília, Brazil and Fundação de Amparo à Pesquisa do Estado de São Paulo (FAPESP), São Paulo, Brazil. EAMG is supported by Coordenação de Aperfeiçoamento de Pessoal de Nível Superior (CAPES) Fellowship. JESJ and RLDM are supported by a CNPq Fellowship.

Received for publication: 27 May 2013.

Revision received: 4 July 2013.

Accepted for publication: 16 August 2013.

This work is licensed under a Creative Commons Attribution NonCommercial 3.0 License (CC BYNC 3.0).

CCopyright E.A.M. de Godoy et al., 2013 Licensee PAGEPress, Italy

Microbiology Research 2013; 4:e6

doi:10.4081/mr.2013.e6

Giardia infection in calves for the first time in Brazil, specifically in the municipality of Lavras, Minas Gerais, where the prevalence was 9\% (11/120). Moreover, Silva Junior et $a l .{ }^{10}$ reported that the frequency of $G$. intestinalis was $25.6 \%$ in the mesoregion of Campo das Vertentes, again in the State of Minas Gerais. In sheep, the prevalence ranges from $1.3 \%$ in Poland, ${ }^{7}$ to $55.6 \%$ in Mexico, ${ }^{11}$ and for goats, the rate varies between $12.3 \%$ in Uganda, ${ }^{12}$ to $42.2 \%$ in Spain. ${ }^{13}$ Studies on the prevalence of infection with Giardia in sheep 
and goats are extremely scarce in Brazil; a rate of infection in goats of $14.3 \%$ was reported in different municipalities of the State of Rio de Janeiro. ${ }^{14}$

Evidence to sustain the zoonotic transmission of Giardia sp is very strong but how often and under what circumstances such transmission occurs has not been determined yet. ${ }^{4}$ Identification of the genetic variations of Giardia sp. is essential to understand its epidemiology, especially in relation to transmission patterns in different geographical areas. ${ }^{15}$

In this study, $G$. intestinalis isolates from humans and animals (domestic and farm) were genetically characterized by the $\beta$-giardin locus with the aim of investigating the prevalence of zoonotic genotypes and the possibility of zoonotic transmission of giardiasis in a municipality in the southeastern region of Brazil. More extensive studies and regional epidemiological surveys are essential to elucidate the transmission dynamics of this protozoan in endemic areas and to assess the level of participation of each host as the source of infection of at-risk individuals and populations. ${ }^{16}$ This work contributes to a better characterization of giardiasis in Araçatuba, São Paulo, Brazil.

\section{Materials and Methods}

\section{Description of the study area}

In the period from July 2009 to October 2010, human (adults and children) and animal fecal samples from the municipality of Araçatuba, São Paulo State were studied. The human fecal specimens were collected in playschools in the outskirts of the city and in private clinical analysis laboratories of the municipal. Animal fecal samples were obtained from the Municipal Animal Shelter and the Veterinary Hospital of the Universidade Estadual Paulista. This city is located $524 \mathrm{Km}$ from the state capital at a latitude of $21^{\circ} 12 ' 32$ " south and a longitude of $50^{\circ} 25 ' 58^{\prime \prime}$ west and at an altitude of $390 \mathrm{~m}$. The climate is semi-arid with rain falling in summer and extremely dry winters when the relative air humidity is $37 \%$. The population of the municipality was 178,927 inhabitants according to the census of $2010 .^{17}$

\section{Study design}

After a detailed explanation of the objectives of the project, adults and the guardians of children signed informed consent forms before being enrolled in the study. Questionnaires on socio-epidemiological data were completed and a single stool sample was collected in $10 \%$ formaldehyde from each participant. Feces of animals were collected after authorization from the managers of the Municipal Animal Shelter and veterinary hospital. The samples were sent to the laboratory of the Microorganisms Research Centre of the Medicine School in São José do Rio Preto (FAMERP) where microscopic examinations and molecular analyses were performed. This work was approved by the Human Research Ethics Committee (FAMERP \#53062008) and by the Animal Experimentation Ethics Commission (FAMERP \#52902008) of FAMERP.

\section{Giardia intestinalis samples}

Single fecal samples were collected from 134 children ( 3 months to 12 years old) and 20 adults (14-54 years old) and placed in 10\% formaldehyde. Additionally, fecal samples were collected from 61 animals: pet cats (10), pet dogs (20), goats (5), sheep (20) and calves (6) and placed in $10 \%$ formaldehyde.

\section{Coproparasitological diagnosis}

The Faust (based on centrifugation and floatation) and Hoffmann, Pons and Janer (based on spontaneous sedimentation) methods, usually employed to detect protozoa and helminthes, were used to detect intestinal parasites. The identification of parasites was by optical microscopy $(10 \times$ and $40 \times$ magnification).

\section{DNA extraction}

The extraction and purification of the genetic material of the parasite were achieved with $200 \mu \mathrm{L}$ of sediment from the Hoffmann, Pons and Janer method. G. intestinalis cysts were concentrated prior to the extraction of DNA.

\section{Cyst concentration}

After the optical microscopic examination, $45 \mathrm{~mL}$ of each thawed sample of fecal material diluted in $10 \%$ formaldehyde was placed in three Falcon tubes $(15 \mathrm{~mL})$. The tubes were centrifuged for three cycles at $2700 \mathrm{~g}$ for 10 minutes. The supernatant was discarded and the pellets from the three tubes of each sample (about two mL of fecal material) were homogenized and placed in a single tube. Then the material was resuspended in about $12 \mathrm{~mL}$ of distilled water to fill the Falcon tube and centrifuged at $2700 \mathrm{~g}$ for 5 minutes. The supernatant was discarded and the pellet was again resuspended in distilled water and centrifuged at $4500 \mathrm{~g}$ for 2 minutes. The supernatant was discarded and the pellet (approximately 1.0-1.5 $\mathrm{mL}$ ) was frozen until the DNA extraction process.

\section{DNA extraction}

The method of Bolano et al. ${ }^{18}$ modified by the association of freeze-thawing in liquid nitrogen and $\mathrm{a} 70^{\circ} \mathrm{C}$ water bath.

Approximately $200 \mu \mathrm{L}$ concentrated fecal material was transferred to a 2-mL plastic tube and $500 \mu \mathrm{L}$ of TENTS was added. Subsequently the tube was immersed in liquid nitrogen $\left(-196^{\circ} \mathrm{C}\right)$ for 5 minutes and then in a water bath at $70^{\circ} \mathrm{C}$. Following this, $200 \mu \mathrm{L}$ of glass beads (acid-washed 425-600 $\mu \mathrm{m}$ glass beads previously separated and autoclaved; Sigma) were added and the tube was stirred in a vortex mixer for two minutes. Again, the tube was immersed in liquid nitrogen for 5 minutes and then in a water bath at $70^{\circ} \mathrm{C}$. This freeze-thawing procedure was performed three time safter which $500 \mu \mathrm{L}$ of phenol and $500 \mu \mathrm{L}$ of chloroform were added and the tube was stirred in a vortex mixer for two minutes. The material was centrifuged at $16,000 \mathrm{~g}$ for 15 minutes and then the upper layer was removed with an automatic pipette and placed in another previously labeled 2-mL tube. A volume of $500 \mu \mathrm{L}$ ice-cold $100 \%$ ethanol was added and the DNA was precipitated at $-20^{\circ} \mathrm{C}$ for one hour. The material was centrifuged at $16,000 \mathrm{~g}$ for 15 minutes and the supernatant was discarded by inversion. The pellet was resuspended in 500 $\mu \mathrm{L}$ TE with RNAse by gently tapping the tube and the material was incubated at $37^{\circ} \mathrm{C}$ for 30 minutes in a water bath. Volumes of $500 \mu \mathrm{L}$ of phenol and $500 \mu \mathrm{L}$ of chloroform were added and the solution was again centrifuged at $16,000 \mathrm{~g}$ for 15 minutes and the liquid layer (top) was transferred using an automatic pipette to another previously labeled $1.5-\mathrm{mL}$ tube. To precipitate the DNA, $20 \mu \mathrm{L}$ of $5 \mathrm{M} \mathrm{NaCl}$ and $500 \mu \mathrm{L}$ ice-cold $100 \%$ ethanol were added and the solution was kept at $-20^{\circ} \mathrm{C}$ for one hour. The solution was again centrifuged at $16,000 \mathrm{~g}$ for 15 minutes and the supernatant discarded by inversion. A volume of $500 \mu \mathrm{L}$ of ice-cold 70\% ethanol was added and again the solution was centrifuged at $16,000 \mathrm{~g}$ for 15 minutes and the supernatant discarded by inversion. The pellet was dried (vertically on a grid) at room temperature for 20 or 30 minutes (or until there were no water droplets) and resuspended in $40 \mu \mathrm{L}$ of TE by gently tapping the tube to elute the DNA. Finally, the DNA was stored in the tube at $-20^{\circ} \mathrm{C}$.

\section{Analysis of the quantity and purity of genomic DNA}

One microliter of each sample was used to quantify the DNA in a NanoDrop® ND-1000 spectrophotometer (Fisher Scientific, Wilmington, USA); the concentration and purity were determined by absorbance at $260 \mathrm{~nm}$ (UV-DNA concentration in $\mu \mathrm{g} / \mathrm{mL}=\mathrm{Abs} \times 100$ $\times 50$ ) and at $280 \mathrm{~nm}$ (quantification of proteins). The ratio between absorbance at 260 $\mathrm{nm}$ and at $280 \mathrm{~nm}$ is indicative of the DNA purity; TE was used as the control. Samples with DNA concentrations of less than $50 \mathrm{ng} / \mu \mathrm{L}$ were subjected to vacuum centrifuge (Vacufuge $^{\mathrm{TM}}, \mathrm{USA}$ ) for 30 minutes. 


\section{Semi-nested PCR}

\section{Identification of the products}

DNA was amplified using the semi-nested PCR technique as described by Volotão et al. ${ }^{19}$ and Cacciò et al. ${ }^{20}$ in a Techne ${ }^{\circledR}$ thermal cycler model Genius (Cambridge, England) with minor modifications. The initial denaturation was of $94^{\circ} \mathrm{C}$ for 5 minutes followed by 35 cycles of $94^{\circ} \mathrm{C}$ for 30 seconds, $63^{\circ} \mathrm{C}$ for 30 seconds and $72^{\circ} \mathrm{C}$ for 1 minutes and with a final extension at $72^{\circ} \mathrm{C}$ for 7 minutes. The first PCR reaction produced a fragment of 753 base pairs (bp). The primers used for this amplification were G7 (5'AAGCCCGACGACCTCACCCGCAGTGC3') and G759 (5'GAGGCCGCCCTGGATCTTCGAGACGAC3'). G759 and G376 primers (5'CATAACGACGCCATCGCGGCTCTCAGGAA3') were used in the second reaction. The fragment obtained in this reaction was $384 \mathrm{bp}$. Both PCR products were separated by $3 \%$ agarose gel electrophoresis (110 volts for 60 minutes). The gel was stained with ethidium bromide. Samples known to be positive for $G$. intestinalis kindly provided by Flávio Paz (Universidade Estadual Paulista, campus de Botucatu, São Paulo, Brazil) and by the Medical Research Laboratory of the Instituto Oswaldo Cruz, Rio de Janeiro, Brazil were used as the positive control. Nuclease-free water (IDT DNA Technologies, Coralville, IA) was used as a negative control in two steps of the amplification.

\section{Restriction fragment polymorphism}

Aliquots (10-12 $\mu \mathrm{L})$ of the PCR products of the $B$-giardin gene (753 bp) were digested with $10 \mathrm{U}$ of the HaeIII enzyme (New England Biolabs Inc.) in a final volume of $20 \mu \mathrm{L}$ at $37^{\circ} \mathrm{C}$ for four hours. Semi-nested PCR products (384 bp) were subjected to a restriction reaction using $10 \mathrm{U}$ of HhaI (New England Biolabs Inc.) under the same conditions. Subsequently, the resulting products were separated by $2.5 \%$ agarose gel electrophoresis, stained with ethidium bromide, analyzed under UV light and photographed in an image analyzer (Transiluminator FBDLT-88). The first digestion (753 bp) produces fragments of 202, 201, 150, 126 and 74 bp characteristic of the A genotype and fragments of 202, 176, 150, 117, 84 and $24 \mathrm{bp}$ for the B genotype. The second digestion (384 bp) was performed to differentiate the AI from the AIV/AIII subgenotypes. While AI is cleaved into fragments of 193, 104, 70 and $17 \mathrm{bp}$, the AII/AIII subgenotypes are cleaved into fragments of 210,70 and $34 \mathrm{bp}$.

\section{DNA and sequencing}

\section{Purification of the DNA}

The semi-nested PCR products were purified using the PCR DNA Purification-GFX ${ }^{\mathrm{TM}}$ and gel band purification kits (GE Healthcare $^{\mathrm{TM}}$, Buckinghamshire, United
Kingdom) following the recommendations of the manufacturer.

\section{Sequencing}

The sequencing reaction used $50 \mathrm{ng}$ of the purified product from the semi-nested reaction (384 bp), $3 \mu \mathrm{L}$ sequencing buffer (Save money 2.5×), 1.0 $\mu$ L BigDye v3.1 (Applied Biosystems, USA) and 10 picomoles of oligonucleotide primer with the total volume being made up to $10 \mu \mathrm{L}$ using bi-distilled water. The reaction consisted of an initial denaturation of $96^{\circ} \mathrm{C}$ for one minute and 39 cycles of $96^{\circ} \mathrm{C}$ for $15 \mathrm{sec}$ onds, $63^{\circ} \mathrm{C}$ for 15 seconds and polymerization at $60^{\circ} \mathrm{C}$ for four minutes; the resulting samples were kept at $4^{\circ} \mathrm{C}$. Subsequently $80 \mu \mathrm{L} 75 \%$ isopropanol were added. After 15 minutes at room temperature, the reactions were centrifuged at $3040 \mathrm{~g}$ for 30 minutes at $20^{\circ} \mathrm{C}$ in a $46 \mathrm{R}$ Rotanta centrifuge (Hettich, USA). After precipitation of the DNA, the supernatant was discarded and the samples washed twice with $200 \mu \mathrm{L}$ of $70 \%$ ethanol followed by centrifugation at $3040 \mathrm{~g}$ for 10 minutes at $20^{\circ} \mathrm{C}$. The samples were vacuum dried, resuspended in $10 \mu \mathrm{L}$ of formamide, denatured for five minutes at $95^{\circ} \mathrm{C}$ and subjected to sequencing in an $\mathrm{ABI} 3730 \mathrm{XL}$ automatic sequencer following the recommendations of the manufacturer (Applied Biosystems, Foster City, California, USA).

\section{Molecular characterization and phyloge- netic analysis}

The sequences were analyzed using the Chromas computer program (http:/www.technelysium.com.au/chromas.htlm) and compared with known sequences of Giardia sp. Multiple alignments of sequences of the $\beta$-giardin gene obtained in this study and of the references listed below, were used to infer phylogenetic relationships using the maximum likelihood (ML) method calculated with the MEGA 5 computer tool. ${ }^{21}$ Branch support was calculated by bootstrap analysis utilizing 1000 replications. ${ }^{22}$ The HKY85 distance was used to estimate divergence, ${ }^{23}$ and the heuristic search algorithm (Nearest neighbor interchange NNI) was used to construct the tree. Reference sequences of the $\beta$-giardin gene of the $G$. intestinalis genotypes are as follows: $\mathrm{AI}$ (AY258617), AII (AY072723), BI (AY072725), BII (AY072726), C (AY545646), D (AY545648), E (AY072729) and F (AY647264).

\section{Results}

\section{Parasitological diagnosis}

The human specimens were positive in $25.3 \%(39 / 154)$ of the cases including $26.8 \%$ (36/134) of children and $15 \%$ (3/20) of adults. Number of parasite ranged from one cyst per
100 microscopic fields to 20 cysts of $G$. intestinalis per microscopic field.

The frequency of $G$. intestinalis among animals studied was $23 \%$ (14/61): four dogs, two adult cats, six sheep, one goat and one calf. Number of parasite ranged from one to three cysts of $G$. intestinalis per 100 microscopic fields.

\section{Genotyping of human and animal isolates}

Amplification of $\beta$-giardin gene fragments was performed for 39 human fecal samples positive for Giardia cysts. Of these, the fragment sizes were as expected for $82 \%(32 / 39$ : 753 bp or 384 bp). The 753 bp PCR product was digested (HaeIII restriction enzyme) resulting in fragments of 202, 201, 150, 126 and $74 \mathrm{bp}$ characteristic of the A genotype. The B genotype was not found in this study. Seven isolates were not amplified. The 384 bp fragment was digested with the HhaI enzyme and 193, 104, 70 and $17 \mathrm{bp}$ fragments were detected. The AI genotype was detected in 10 isolates, while the AII/AIII genotypes were evidenced in 22 samples with fragments of 210,70 and $34 \mathrm{bp}$. Of these, three products obtained from the seminested PCR reaction (human isolates 70, 127 and 138) were sequenced and compared with sequences of the main $G$. intestinalis genotypes. These analyses confirmed that Giardia sp. involved in the infection of the studied human population was of the A genotype (specifically AI).

Amplification of $\beta$-giardin gene fragments was performed for 14 pet fecal samples positive for Giardia cysts. Of these, $43 \%$ (6/14; 4 dogs and 2 cats) had the expected fragment sizes (384 bp). However, for 57\% (8/14) of farm animals found positive at microscopic examination (i.e. six sheep, one goat and one calf), no PCR product was amplified using the current protocol. The six isolates from animals which had 384 bp fragments were digested with the HaeIII restriction enzyme and all had fragments compatible to the AI genotype of $G$. intestinalis. The semi-nested PCR reaction products of the isolates (cat 4, cat 5, dog 1 dog 59 and $\operatorname{dog} 374$ ) were sequenced and compared with main genetic groups of $G$. intestinalis. These analyses confirmed that the animal population was infected by Giardia sp. with the AI genotype. The fragment was not detected in any negative control during the both steps of the methodology.

\section{Phylogenetic analyses of Giardia}

The sequences of $\beta$-giardin gene fragments of the different genotypes of $G$. intestinalis found in this study were compared with sequences stored in GenBank. Phylogenetic analyses provided strong evidence (99\%) that the $G$. intestinalis isolates with $\mathrm{AI}$ genotypes 
from humans should be placed in the same cluster as the isolates from animals (Figure 1). The sequences obtained were registered in the GenBank database under access numbers JQ247026 (isolate 59), JQ247027 (isolate 374) and JQ247028 (isolate 1) for the isolates from dogs, JQ247029 (isolate 4) and JQ247030 (isolate 5) for the isolates from cats, and JQ247031 (isolate 70), JQ247032 (isolate 127) and JQ247033 (isolate 138) for the isolates from humans.

\section{Discussion and Conclusions}

G. intestinalis are intestinal protozoan parasites that have a cosmopolitan distribution and are widely prevalent in humans and in many species of mammals, including pets and farm animals. The frequency of giardiasis is higher in developing countries than in developed countries. ${ }^{24,25}$ This protozoan, unlike schistosomiasis, more frequently affects children of families with higher monthly incomes due to the higher consumption of vegetables. ${ }^{26}$ Another important factor in the spread of giardiasis is that this parasite is often found in collective environments as direct transmission by person-person contact increases the chances of contamination. ${ }^{27}$ Our results are similar to most reported for children in the State of São Paulo and other States of Brazil. ${ }^{28-31}$ We cannot discard the possibility that the rates of giardiasis detected may be related to biological characteristics of the parasite, elimination of which is intermittent; the fact that only one sample was collected from each individual may have contributed to a lower prevalence in the human population. On the other hand, it is known that giardiasis is more frequent in children than adults, ${ }^{32}$ a fact that was observed in the samples collected in Araçatuba, where the majority of the studied population was young (87\%).

The prevalence observed in the dog population agrees with reported infection rates worldwide, ${ }^{33,34}$ and in the variation reported in Brazil, which ranging from $0.8 \%$ to $36.8 \%{ }^{35-38}$ On the other hand, the prevalence of Giardia sp. is less studied in cats than in dogs. However, data available in the literature show variation from $2 \%$ in Australia to $44.4 \%$ in the USA. $^{39,40}$ The rate in this work was $20 \%$; publications in Brazil show a variation from 3.5\% to 28.4\%. ${ }^{41,42}$ A possible explanation for this fact may be related to the low elimination of cysts in feces of these animals, which are not detectable by microscopic methods.

The infection rate of farm animals by $G$. intestinalis found in our study was similar to published rates for other Brazilian regions. ${ }^{9,10}$ In the current work, the infection rates were
$20 \%$ and $30 \%$ for goats and sheep, respectively. As previously described in respect to infections by this parasite in humans, it is believed that biological and methodological factors may lead to an underestimation in the detection of this protozoan in animals.

G. intestinalis has a high level of genetic diversity with seven genotypes: A, B, C, D, E, F and G. Interestingly, only the A genotype and its respective subgenotypes (AI and AI//II) were detected in this study with no samples presenting the B genotype. However, in the southeastern region of the State of São Paulo at $400 \mathrm{Km}$ from Araçatuba, Souza et al. ${ }^{16}$ detected the $\mathrm{B}$ genotype in human feces. This genotype was also detected in human feces in Argentina and in France. ${ }^{43,44}$ Nevertheless, studies conducted in Portugal, ${ }^{45}$ Mexico, ${ }^{2}$ and Rio de Janeiro also in southeastern Brazil (850 Km northwest of São Paulo) only detected the A genotype in human fecal samples. ${ }^{46}$

Phylogenetic analyses of the $\beta$-giardin gene of $G$. intestinalis grouped the human and animal isolates within the same AI subgenotype cluster thus corroborates our classification by PCR-RFLP. A case of associated $G$. intestinalis infections of a child and his dog was described in the State of Rio de Janeiro as both isolates were characterized as the AI genotype which suggests that despite the low incidence, there is the possibility of a zoonotic cycle. In this work, the absence of the $B$ genotype may be due to, as was suggested in a previous publication, the fact that not all the cysts found using the coproscopic technique were identified by the molecular methodology. ${ }^{19}$ In addition, it is known that these parasite cysts are eliminated intermittently in feces and that the fecal material may contain DNA polymerase inhibitors, which may impair the final amplification.

In respect to animals, the AI subgenotype was detected in the city of Rio de Janeiro in fecal samples of dogs and pet cat, ${ }^{19}$ and the AI and $\mathrm{F}$ genotypes were found in fecal samples of pet cats and C (25.9\%) and D genotypes in isolates from dogs in the southeast of the State of São Paulo. ${ }^{16}$ On the other hand, research conducted in the municipality of Botucatu, also in the State of São Paulo, reported that only specific $\mathrm{C}$ and $\mathrm{D}$ genotypes, either in isolation or as mixed infections, were detected in dogs. ${ }^{47}$ Recently, in São José do Rio Preto, northwestern São Paulo State, all the detected isolates of $G$. intestinalis have been of the A genotype in humans and dogs (AI and AII subgenotype) showing the presence of zoonotic genotypes in the canine population of the region. ${ }^{48}$

In this work in the city of Araçatuba, all the positive results were compatible with the $\mathrm{AI}$ genotype of $G$. intestinalis. Although the farm animal genotype of $G$. intestinalis (E) seems to be the commonest in cattle, studies in Canada and Australia have shown that a small proportion of cattle in a herd can be hosts of the A genotype, the most common human genotype.$^{8,49}$ According to previous studies, isolates from sheep and goats show that the E genotype is the most frequently detected. In the current work, sheep, goats and cattle were positive for $G$. intestinalis at light microscopy, however, by PCR none of these animals presented fragments compatible with the zoonotic genotypes

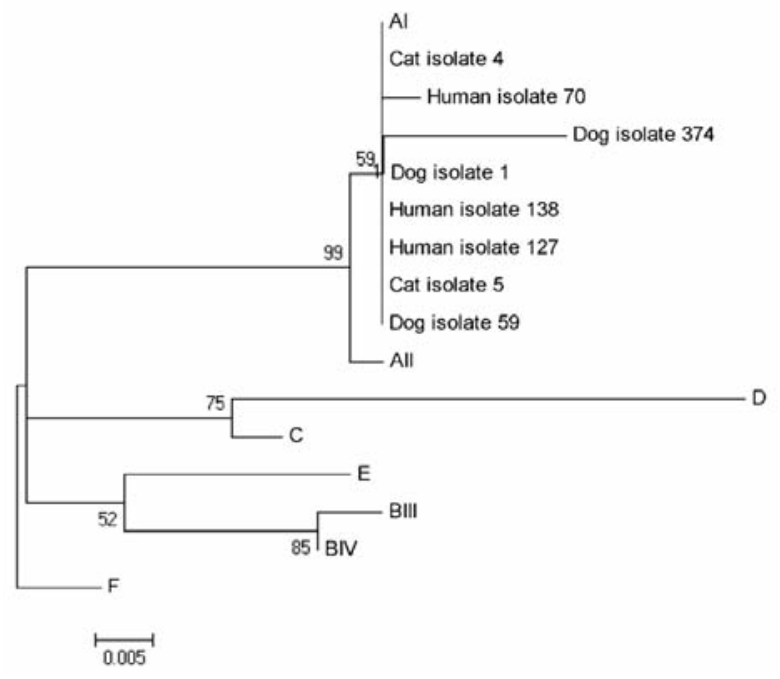

Figure 1. Phylogenetic relationship between $ß$-giardin gene sequences of isolates from human samples $(70,127,138)$, dogs $(1,59,374)$ and cats $(4,5)$. The tree was built using the maximum likelihood (HKY) method of the MEGA 5 computer program. Cluster analysis was by the bootstrap test (1000 replications). 
of the parasite (A and B). One hypothesis to explain these findings is that the parasite of the calves, goats and sheep may have speciesspecific genotypes which are not detected by the molecular protocol used in this study. ${ }^{50}$ Thus, farm animals in this region are not a concern in respect to zoonotic transmission of giardiasis. For the first time, this study presents information on the presence of the genotypes of $G$. intestinalis and the potential of zoonotic transmission of this intestinal protozoan in the city of Araçatuba, northwestern São Paulo State, Brazil. As the A genotype (AI and AII/AIII) was detected in pets and humans in the city of Araçatuba, we can assume that only zoonotic genotypes are circulating in this animal population in the region. Therefore, the distribution of genotypes may be related to intrinsic factors between the parasite and host and that environmental and climatic factors can influence the epidemiology of the protozoan in the region. Indeed, molecular studies on Giardia infections in indigenous communities showed that this protozoan is as common in dogs as in people but almost all dogs carry a species-specific genotype. This is different to urban areas, where dogs are infected with zoonotic A and B genotypes. The levels of infection in these communities are higher than in urban areas and so the dogs are exposed to similar frequencies of both specific and zoonotic genotypes. However, species-specific genotypes are better adapted to dogs and thus compete better than other genotypes of Giardia in urban and domestic environments. Hence, the frequency of transmission from dog to dog would be less frequent and acquired infections of zoonotic genotypes in dogs would also be more likely to persist. ${ }^{51}$ Interestingly, the same genotypes were found in the municipalities of Araçatuba and São José do Rio Preto,${ }^{48}$ which have similar climatic characteristics and geographical locations as both are in the northwestern region of São Paulo State. The feces of most of the pets in this study were from a local animal shelter, and therefore, from strays and abandoned animals. The detection of the zoonotic AI genotype in all these animals suggests that these may be the main participants in the transmission cycle of giardiasis to man in the region. In addition, similar to reports by Katagiri and Oliveira-Sequeira (2008), ${ }^{6}$ lack of knowledge of the owners of the few pets included in this study about the zoonotic potential of transmission of intestinal parasites, hinders the use of control and prophylaxis measures and may account for the apparent negligence in respect to this parasite.

In this study, genotypes of $G$. intestinalis considered zoonotic were detected circulating in pets and humans from the city of Araçatuba, Brazil, suggesting the possibility of zoonotic transmission of this parasite in the region. The absence of zoonotic (AI, AII/AIII and B) genotypes in farm animals of this study suggests that they are not involved in the chain of transmission of $G$. intestinalis to man in the region, probably because they are carriers of the specific E genotype.

\section{References}

1. Rossit AR, Almeida MT, Nogueira CA, et al. Bacterial, yeast, parasitic, and viral enteropathogens in HIV-infected children from São Paulo State, Southeastern Brazil. Diagn Microbiol Infect Dis 2007;57:59-66.

2. Lalle M, Jimenez-Cardosa E, Cacciò SM, et al Genotyping of Giardia duodenalis from humans and dogs from Mexico using a betagiardin nested polymerase chain reaction assay. J Parasitol 2005;91:203-5.

3. World Health Organization. Division of Control of Tropical Diseases. Intestinal Parasites Control: geographical distribution 2006. Available from: http://www. who.int/ctd/html/intestburtre.html.

4. Thompson RCA. The zoonotic significance and molecular epidemiology of Giardia and giardiasis. Vet Parasiltol 2004;126:15-35.

5. Macpherson CNL. Human behavior and the epidemiology of parasitic zoonoses. Int. J Parasitol 2005;35:1319-31.

6. Katagiri S, Oliveira-Sequeira TCG. Prevalence of dog intestinal parasites and risk perception of zoonotic infection by dog owners in São Paulo State, Brazil, Zoon Pub Health 208;55:406-13.

7. Bajer A. Cryptospodiduim and Giardia spp. Infections in humans, animals and the environment in Poland Parasitol Res 2008;104:1-17.

8. O'handley RM, Olson ME, Fraser D, et al. Giardia in dairy calves from Western Australia and Western Canada. Vet Parasitol 2000;90:193-200.

9. Guimarães AM, Guedes E, Carvalho RA. Ocorrência de Giardia spp. em bezerros leiteiros no Brasil. Arq Bras Vet Zootec 2001;53:652-53.

10. Silva Junior FA, Carvalho AHO, Rocha CMBM, et al. Fatores de risco associados à infecção por Cryptosporidium spp. e Giardia duodenalis em bovinos leiteiros na fase de cria e recria na mesorregião do Campo das Vertentes de Minas Gerais. Pesq Vet Bras 2011;31:690-6.

11. Di Giovanni GD, Betancourt WQ, Hernadez $\mathrm{J}$, et al. Investigation of potential zooanthroponotic transmission of cryptosporidiosis and giardiasis througt agricultural use of reclaimed wastewater. Int J Environ Health Res 2006;16:405-18.

12. Jhonston AR, Gillespie R, Rwego IB, et al. Molecular epidemiology of cross-species
Giardia duodenalis transmission in western Uganda. PLoS Trop Dis 2010;4:e683.

13. Gomez-Munoz MT, Navarro TC, GarijoToldedo MM, et al. Ocurrence and genotypes of Giardia isolated from lambs in Spain. Parasitol Int 2009;58:297-9.

14. Bonfim TCB, Huber F, Gomes SR, et al. Infecção natural por Giardia em caprinos com aptidão leiteira na região serrana do Estado do Rio de Janeiro. Rev Bras Parasitol Vet 2004;13:89-95.

15. Guimarães S, Sogayar MI, Franco MF. Giardia duodenalis: interstrain variability of proteins, antigens, proteases, isoenzymes and nucleic acids. Rev Inst Med Trop 1999;41:45-8.

16. Souza SLP, Gennari SM, Richtzenhain LJ, et al. Molecular identification of Giardia duodenalis isolates from humans, dogs, cats and cattle from the state of São Paulo, Brazil, by sequence analysis of fragments of glutamate dehydrogenase (gdh) coding gene. Vet Parasitol 2007;149:258-64.

17. IBGE. Instituto Brasileiro de Geografia e Estatística. Available from: http:/ /www.censo2010.ibge.gov.br/dados_divulgados/index.php?uf=35. Accessed: December 2011.

18. Bolano A, Stinchi S, Preziosi R, et al. Raid methods to extract DNA and RNA from Cryptococcus neoformans. FEMS Yast Res 2001;1:221-4.

19. Volotão AC, Costa-Macedo LM, Haddad FSM. Genotyping of Giardia duodenalis from human and animal samples from Brazil using $\beta$-giardin gene: a phylogenetic analysis. Acta Trop 2007;102:10-9.

20. Cacciò S, De Giacomo M, Pozio E. Sequence analysis of the $\beta$-giardin gene and development of a polymerase chain reaction-restriction fragment length polymorphism assay to genotype Giardia duodenalis cysts from human fecal samples. Intern J Parasitol 2002;32:1023-30.

21. Tamura K, Peterson D, Peterson N, et al. MEGA5: molecular evolutionary genetics analysis using maximum likelihood, evolutionary distance, and maximum parsimony methods. Mol Biol Evol 2011;28: 2731-9273.

22. Felsenstein J. Confidence limits on phylogenies: an approach using the bootstrap. Evolution 1985;39:783-91.

23. Hasegawa MM, Kishino H, Yano T. Dating of the human-ape splitting by molecular clock of mitochondrial DNA. J Mol Evol 1985;21:160-74.

24. Cimerman S, Cimerman B, Lewi DS. Prevalence of intestinal parasitic infections in patients with acquired immunodeficiency syndrome in Brazil. Int $\mathbf{J}$ Infect Dis 1999;3:203-6.

25. Gonçalves AC, Gabbay YB, Mascarenhas JD, et al. Calicivirus and Giardia lamblia 
are associated with diarrhea in human immunodeficiency virus-seropositive patients from southeast Brazil. Am J Trop Med Hyg 2009;81:463-46.

26. Santos RCV, Hoerlle JL, Aquino, ARC, et al. Prevalência de enteroparasitoses em pacientes ambulatoriais do Hospital Divina Providência de Porto Alegre, RS. Rev Bras Anal Clin 2004;36:241-3.

27. Machado CR, Marcari EL, Cristante S, et al. Giardíase e helmintíases em crianças de creches e escolas de $1^{\circ}$ e $2^{\circ}$ graus (públicas e privadas) da cidade de Mirassol (SP, Brasil). Rev Soc Bras Med Trop 1999;32:697-704.

28. Machado RLD, Figueredo MC, Frade AF, et al. Comparação de quatro métodos laboratoriais para diagnóstico da Giardia lamblia em fezes de crianças residentes em Belém, Pará. Rev Soc Bras Med Trop 2001;34:91-3.

29. Schnnack FJ, Fontana LM, Barbosa PR, et al. Enteropatógenos associados com diarréia infantil ( $<5$ anos de idade) em amostra da população da área metropolitana de Criciúma, Santa Catarina. Cad Sau Pub 2003;19:1205-8

30. Menezes AL, Lima VMP, Freitas MTS, et al. Prevalence of intestinal parasites in children from public daycare centers in the city of Belo Horizonte, Minas Gerais. Brazil. Rev Int Med Trop 2008;50:57-9.

31. Belloto MVT, Junior JES, Macedo EA, et al. Enteroparasitoses numa população de escolares da rede pública de ensino do Município de Mirassol, São Paulo, Brasil. Rev Pan-Amaz Saude 2011;2:37-44.

32. Mascarini LM, Donalísio MR. Giardiasis and cryptosporidiosis in children institutionalized at daycare centers in the state of São Paulo. Rev Soc Bras Med Trop 2006;39:577-9.

33. Traub RJ, Inpankaew T, Reid SA, et al. Transmission cycles of Giardia duodenalis in dogs and humans in temple communities in Bangkok-a critical evaluation of its prevalence using three diagnostic tests in the field in the absence of a gold standard. Acta Trop 2009;111:125-32.

34. Olson ME, Leonard NJ, Strout J. Prevalence and diagnosis of Giardia infection in dogs and cats using a fecal antigen test and fecal smear. Can Vet J 2010;51: 640-2.

35. Huber F, Bomfim TC, Gomes RS. Comparison between natural infection by Cryptosporidium spp., Giardia spp. in dogs in two living situations in the West Zone of the municipality of Rio de Janeiro. Vet Parasitol 2005;130:69-72.

36. Mundim MJS, Rosa LAG, Hortêncio SM, et al. Prevalence de Giardia duodenalis and Cryptosporidium spp. in dogs from different living conditions in Uberlândia, Brazil Vet Parasitol 2007;44:356-9.

37. Meireles P, Montiani-Ferreira F, ThomazSoccol V. Survey of giardiasis in household and shelter dogs from metropolitan area of Curitiba, Parana state, Southern Brazil. Vet Parasitol 2008;52:242-8.

38. Klimpel S, Heukelbach J, Pothmann D, et al. Gastrointestinal and ectoparasites from urban stray dogs in Fortaleza (Brazil): high infection risk for humans? Parasitol Res 2010;107:713-9.

39. Palmer CS, Traub RJ, Robertson ID, et al. Determining the zoonotic significance of Giardia and Cryptosporiduim in Australian dogs and cats. Vet Parasitol 2008;154:1427.

40. Fayer R, Santin M, Trout JM, et al. Detection of Cryptosporidium felis and Giardia duodenalis Assemblage $\mathrm{F}$ in a cat colony. Vet Parasitol 2006;140:44-53.

41. Lorenzini G, Tasca T, De Carli GA. Prevalence of intestinal parasites in dogs and cats under veterinary care in Porto Alegre, Rio Grande do Sul, Brazil. Braz. J Vet Res Anim Sci 2007;44:137-45.

42. Mendes-de-Almeida F, Silva MMO, Labarthe N. Giardia spp. em amostras fecais de gatos domésticos do Rio de Janeiro, RJ. Acta Sci Vet 2007;35:468-9.

43. Minvielle MC, Molina NB, Polverino D, et al. First genotyping of Giardia lamblia from human and animal feces in Argentina, South America. Mem Inst Oswaldo Cruz 2008;103:98-103.

44. Bertrand I, Albertini L, Schwartzbrod J. Comparison of two target genes for detection and genotyping of Giardia lamblia in human feces by PCR and PCR- restriction fragment length polymorphism. J Clin Microbiol 2005;43:5940-4.

45. Sousa MC, Morais JB, Machado JE, et al. Genotyping of Giardia lamblia human isolates from Portugal by PCR-RFLP and sequencing. J Eukaryot Microbiol 2006;53 Suppl 1:S174-6.

46. Silva RR, da Silva CAM, Pereira CAJ, et al. Association between nutritional status, environmental and socio-economic factors and Giardia lamblia infections among children aged 6-71 months in Brazil. Trans Soc Trop Med Hyg 2009;103:512-9.

47. Paz e Silva F, Monobe MM, Lopes R, et al. Molecular characterization of Giardia duodenalis in dogs from Brazil. Parasitol Res 2012;110:325-34.

48. Volotão AC, Ramos NMD, Fantinatti M, et al. Giardiasis as zoonosis: between proof of principle and paradigm in the Northwestern region of São Paulo State, Brazil Braz Infect Dis 2011;15:382-3.

49. Appelbee AJ, Frederic LM, Heitman TL, et al. Prevalence and genotyping of Giardia duodenalis from beef calves in Alberta, Canada. Vet Parasitol 2003;122:289-94.

50. Robertson LJ. Review article: Giardia and Cryptospodium in sheep and goats: a review $F_{0}$ the potential for transmission to humans via environmental contamination. Epidemiol Infect 2009;137:913-21.

51. Thompson RCA. Giardiases as a re-emerging infectious disease and its zoonotic potential. Int J Parasitol 2000;30:1259-67. 